Mini Review

\title{
A study on the bandage production process of Bangladesh
}

\begin{abstract}
The aim of this paper is to study the bandage production process of Bangladesh. Bangladesh, a destiny of self-development and self-employment, where low price medicated textile product, Bandage has been producing near kakshiali river at Nolta in the kaligonj Upzilla of Satkhira district. All the process of bandages up to packaging is conducting by local manufacturer. This product has brought alight of employment for both men \& women of Nolta. Women are directly involved in the manufacturing process in home whereas men are working at outside. This paper shows a simple and one of the cheapest manufacturing process of bandage.
\end{abstract}

Keywords: bandage, warp preparation, weft preparation, weaving process
Volume 6 Issue 5 - 2020

\author{
Shaikh Md Mominul Alam,' Tanvir Alam,' \\ Abdullah Al Faruque, ${ }^{2}$ Shariful Islam ${ }^{3}$ \\ 'Department of Textile Machinery Design and Maintenance, \\ Faculty of Science and Engineering, Bangladesh University of \\ Textiles, Bangladesh \\ ${ }^{2}$ Department of Fabric Engineering, Faculty of Textile \\ Engineering, Bangladesh University of Textiles, Bangladesh \\ ${ }^{3}$ Department of Textile Engineering, Faculty of Science and \\ Engineering, City University, Bangladesh
}

\begin{abstract}
Correspondence: Shaikh Md Mominul Alam, Department of Textile Machinery Design and Maintenance, Faculty of Science and Engineering, Bangladesh University of Textiles, Tejgaon, Dhaka I208, Bangladesh, Tel +88 0I7|3 I7|365,

Email dalim70@yahoo.com
\end{abstract}

Received:September 19, 2020 | Published: October 19, 2020

\section{Introduction}

The chief raw material for medical bandage production is bleached cotton gauge fabric of appropriate quality, compatible to IS-758/1925. ${ }^{1}$ The width of fabric varieties from 2.5 to $15 \mathrm{~cm}$ and length from 3 to 4 meter. $^{2}$ The fabric which is used to make Medical Dressing is to be obtained from native marketplace. ${ }^{3}$

Generally yarn is purchased from Naryangonj, the biggest market of lot mixed yarn in cone package form. ${ }^{4}$ Normally $30^{\mathrm{s}}, 24^{\mathrm{s}}$ PC (90\% polyester \& $10 \%$ cotton) yarn or $100 \%$ cotton yarn of similar count are used for producing bandage..$^{5}$ Figure 1 shows the yarn storage area.

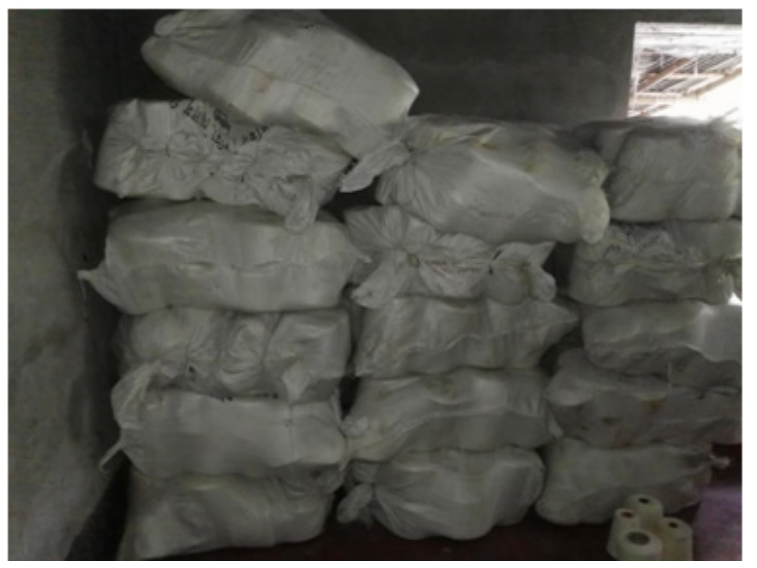

Figure I Yarn storage area.

Surgical bandage manufacture task can be originated on a small scale with reasonable venture. ${ }^{6}$ The mandate for Surgical Bandage is seen all throughout the year. ${ }^{7}$ The surgical bandage is the goods prepared from white bleached cotton gauge fabric of apposite quality. ${ }^{8}$

The surgical bandage found in roll form in the area of 3 to 4 meters. ${ }^{9}$
With correct Machinery, you can sort Surgical Bandage and can stream remits in hospitals, clinics, medical stores, health shop etc. ${ }^{10}$

To making these products, a person should learn surgical bandage making procedure properly. ${ }^{11}$ Then he should select a Location for Surgical Bandage production. Then he should arrange a Bandage Business Project Plan. ${ }^{12}$ Then he should arrange finance and legal compliance. Then he should set up machineries. ${ }^{13}$ After that he should buy raw materials. ${ }^{14}$ Then he should promote his business plan. After that he should search for customers to sell his products. This is the production sequence of making bandage. ${ }^{15}$

To produce bandage products, one should learn bandage manufacturing process properly. ${ }^{11}$ A new investor should select a location where skill manpower is present ${ }^{12}$ and arrange simple machineries as describe later. ${ }^{13}$ Yarn as a main raw material can arrange from export oriented knitting and woven fabric manufacturing industries at a cheaper price ${ }^{14}$ and produce woven bandage fabric by following procedure as describe below. ${ }^{15}$

\section{Bandage production process}

\section{Preparatory process}

Warp preparation: Conventional Handmade Wooden Warping Machine.

Weft Preparation: Pirn Winding Machine

\section{Warp preparation process}

The cone packages of yarn are placed in front of the warping machine which is a wooden hollow charka .At first to form a band a specific no. of ends are getting passed from the reed gap. ${ }^{16}$ Then the band are formed like a knot which is hooked up on the wooden charka. The charka is driven by a motor or by hand .Charka has by and large $3 \mathrm{~m}$ circumference. ${ }^{17}$ So, warping is done according to weaving requirement $150-200 \mathrm{~m}$ warp yarn.5-6 bands are wrapped 
around charka. Here total ends are almost $700-800 .{ }^{18}$ Then total warp is transferred to a wooden beam. Figures $2-4$ shows warp preparatory process.

\section{Weft preparation process}

Pirn winding machine is used for weft preparation. It is fully motor driven.

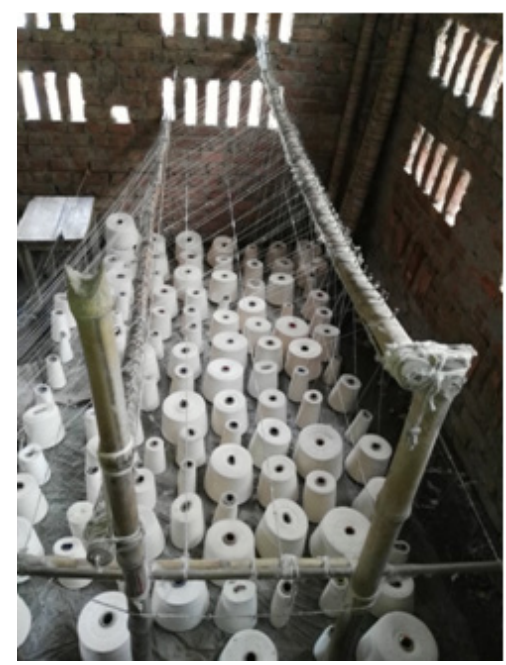

Figure 2 Cone package for warping.

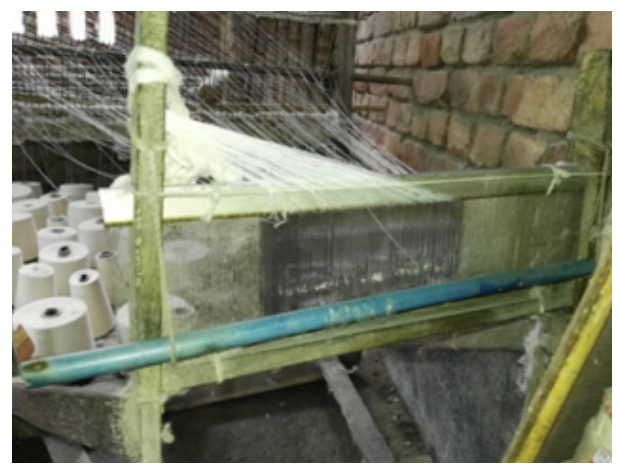

Figure 3 Reed for passing yarn to form band.

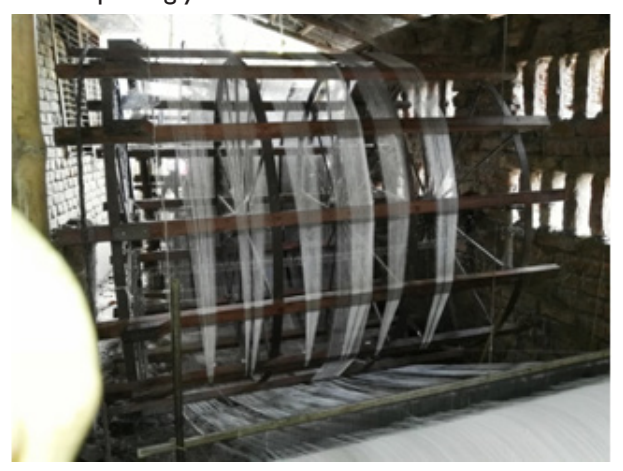

Figure 4 Band warping \& beaming.

\section{Weaving process}

Weaving bandage fabric is totally done by conventional negative tappet loom .fabric construction naturally $24^{\mathrm{s}} \times 24^{\mathrm{s}} / 18 \times 12=36$ ", $30^{\mathrm{s}} \times 30^{\mathrm{s}} / 18 \times 16=36$ ", $30^{\mathrm{s}} \times 30^{\mathrm{s}} / 36 \times 28=36$ " $30+24 \times 30+24 / 18 \times 16=36$ ". ${ }^{19}$ Only a single motor is used for total mechanism and connected to household electric line of 220volt (Figure 5). ${ }^{20}$
Here weft insertion system is under pick mechanism (Figure 6). Beating mechanism is crank beat up (Figure 7).

Let off mechanism is negative (Figure 8) (Figure 9).

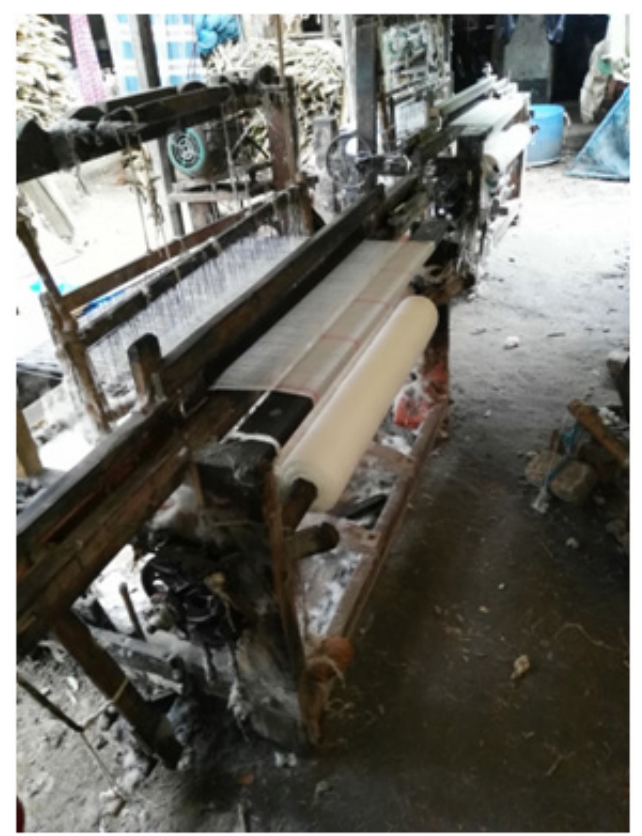

Figure 5 Conventional loom negative tappet shedding mechanism.

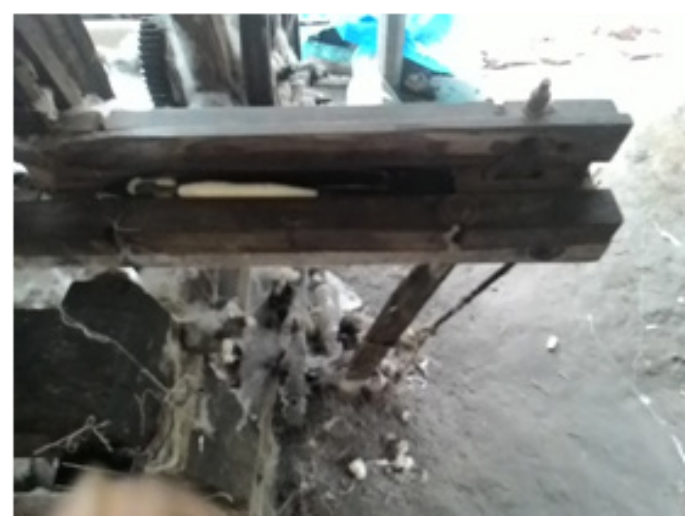

Figure 6 Picking system.

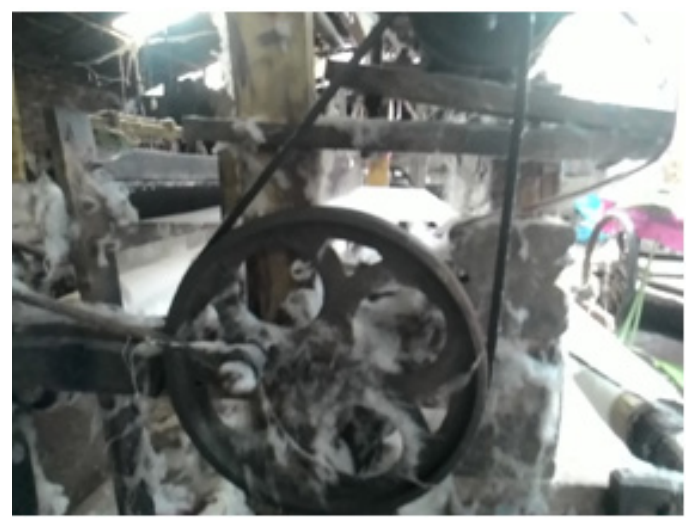

Figure 7 Beat up system. 


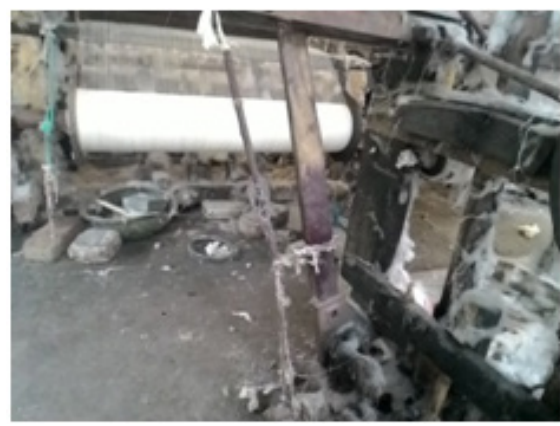

Figure 8 Let off system.

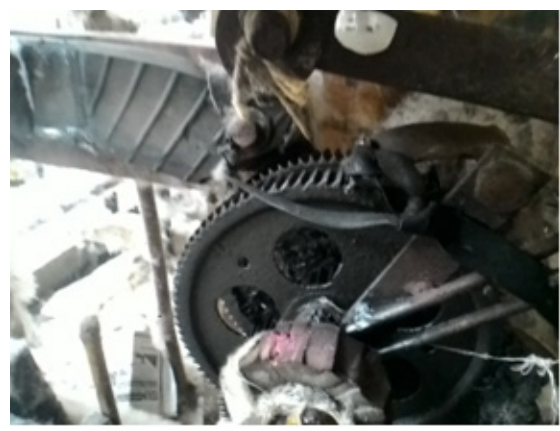

Figure 9 Weel take up mechanism.

\section{Wet processing}

Accumulated gauge are placed on earth made huge bowl 'Nanda' in which the bottom portion is perforated which is placed on water vapour processing system on fire place temperatre almost $100^{\circ} \mathrm{C}$ (Figure 10) (Figure 11). ${ }^{21}$

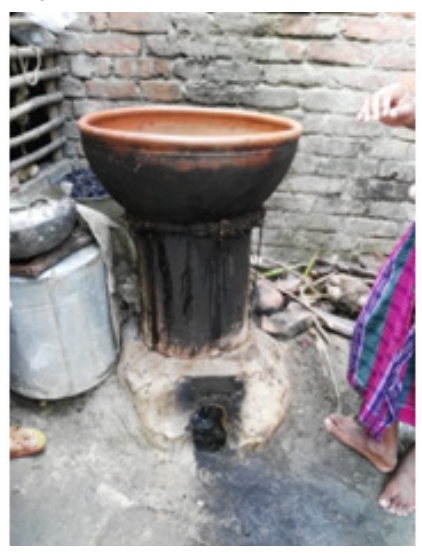

Figure I0 Nanda homemade boiler.

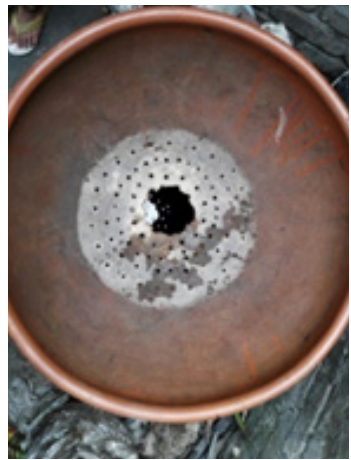

Figure I I Earth made bowl perforated.

\section{Scouring and bleaching process flow}

At first take $18 \mathrm{yd} \times 100 \mathrm{pcs}$ bandages soaking in normal water (120ltr), then take $3.5 \mathrm{~kg}$ bleaching powder mixing water soaked bandage in a house. ${ }^{22}$ Then take $3.5 \mathrm{~kg}$ baking soda mixing in that house. ${ }^{23}$ Then rinsing was done with foot wearing and rubber gumboot. Then it was kept for 6 hours. ${ }^{24}$ After that hand washing was done in pond \& drying under open sky (Figure 12). ${ }^{25}$

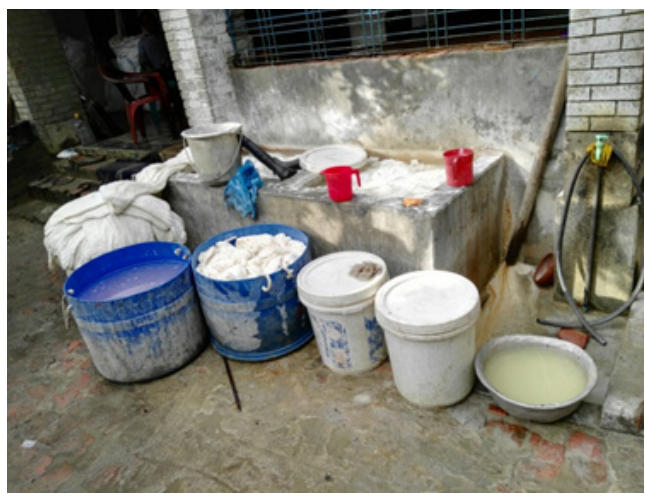

Figure 12 Wet processing of bandages.

Sized bandages: According to buyer's order sometimes bandages are needed to be sized .In this process bleached bandages are placed in drum where a mixture Barley powder with water at a ratio of 1:10. Then it is rinsed by hand \& dried under open sky. ${ }^{26}$

\section{Sales \& distribution process}

Bandages are sold in various systems: - pieces, in weight, per yard etc. Manufacturers are selling at a rate of around 5.5bdt /yd. Wholesaler after purchasing from manufacturers make process in autoclave for sterilizing. Then packing unit makes packing as per consumers interest (Figure 13). ${ }^{27}$

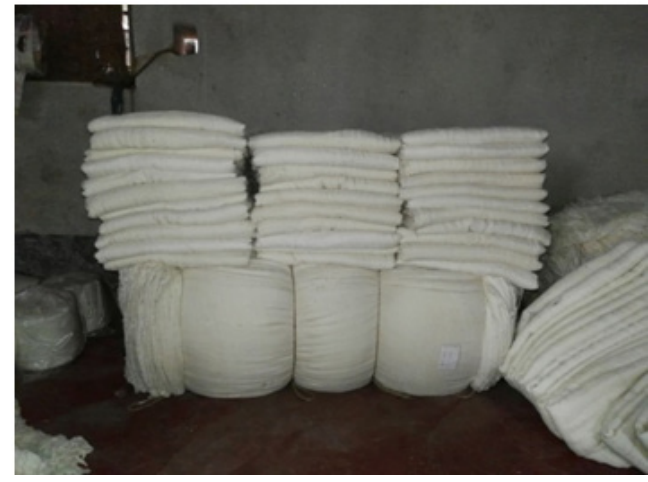

Figure 13 Storage area.

\section{Conclusion}

It has been seen from the papers that, the production process of bandages were briefly discussed. In hospitals or as a first aid item bandages are always an essential item. This product is sold in retail market at high price but the manufacturers are having less. If govt. comes forward to patronize them by providing loan or incentives this sector will become a promising sector to contribute to national GDP. Bandage is an important product for hospitals, clinics and medical stores. It should be produced properly to reduce further hassle like allergy or infection. This paper opens possible ways for the manufacture of bandage commercially. 


\section{Acknowledgments}

None.

\section{Funding}

None.

\section{Conflicts of interest}

The authors have no conflicts of interest regarding the publication of this paper.

\section{References}

1. Hatamie A, Angizi S, Kumar S, et al. Textile based chemical and physical sensors for healthcare monitoring. Journal of The Electrochemical Society. 2020;167(3):037546.

2. Nair S, Day M, Godbole G, et al. Genomic surveillance detects Salmonella enterica serovar Paratyphi A harbouring bla CTX-M-15 from a traveller returning from Bangladesh. Plos one. 20201;15(1): 0228250.

3. Ticar BF, Rohmah Z, Neri TAN, et al. Biocompatibility and structural characterization of glycosaminoglycans isolated from heads of silverbanded whiting (Sillago argentifasciata Martin \& Montalban 1935). International Journal of Biological Macromolecules. 2020;151:663676.

4. Fontenot KR, Edwards JV, Haldane D, et al. Structure/function relations of chronic wound dressings and emerging concepts on the interface of nanocellulosic sensors. Lignocellulosics. 2020:249-278.

5. Al-Jaibaji O, Swioklo S, Shortt A, et al. Hypothermically stored adipose-derived mesenchymal stromal cell alginate bandages facilitate use of paracrine molecules for corneal wound healing. Int J Mol Sci. 2020;21(16):5849.

6. Olaniran O, Garcia C, Li W, et al. Amylase loading on a commercial nylon bandage intended for the control delivery of drug in treating localized wounds. Materials Today: Proceedings. 2020.

7. Gore DM, Leucci MT, Koay SY, et al. Accelerated pulsed high-fluence corneal cross-linking for progressive keratoconus. American Journal of Ophthalmology. 2020.

8. Mansoorianfar M, Shahin K, Mirström MM, et al. Cellulose-reinforced bioglass composite as flexible bioactive bandage to enhance bone healing. Ceramics International. 2020.

9. Baker BD, Palacios KE. Occupational health, industrial hazards, vulnerability assessment, and self-assessment. The Professional Protection Officer, Butterworth-Heinemann. 2020:59-71.

10. Losego MD, Leng CZ, Piercy BD, 2019. Process to chemically modify polymeric materials by static, low-pressure infiltration of reactive gaseous molecules. U.S. Patent. 2019.

11. Ticar BF, Rohmah Z, Neri TAN, et al. Biocompatibility and structural characterization of glycosaminoglycans isolated from heads of silverbanded whiting (Sillago argentifasciata Martin \& Montalban 1935). International Journal of Biological Macromolecules. 2020;151:663676.

12. Seitz BD, Lavon GD, Menner J, et al. Length-to-side and hip-to-waist silhouettes of adult disposable absorbent articles and arrays. U.S. Patent 10,485,712. 2019
13. Altun E,Aydogdu MO, Crabbe-Mann M, et al. Co-culture of keratinocytestaphylococcus aureus on $\mathrm{Cu}-\mathrm{Ag}-\mathrm{Zn} / \mathrm{CuO}$ and $\mathrm{Cu}-\mathrm{Ag}-\mathrm{W}$ nanoparticle loaded bacterial cellulose: PMMA bandages. Macromolecular Materials and Engineering. 2019;304(1):1800537.

14. Kolpakhchyan PG, Lobov BN, Mikitinskiy AP, et al. The production possibility of permanent magnet high speed electric generator rotors. 2018 X International Conference on Electrical Power Drive Systems (ICEPDS); 2018:1-5.

15. Metzner M, Bickel B, Mayr A, et al. Simulation-assisted method for evaluating innovative production technologies for electric traction motors. 018 8th International Electric Drives Production Conference (EDPC); 2018:1-5.

16. Konwar A, Kandimalla R, Kalita S, et al. Approach to fabricate a compact cotton patch without weaving: A smart bandage material. ACS Sustainable Chemistry \& Engineering. 2018;6(5):5806-5817.

17. Houde AY, Harrington DL, Pamperin MT, et al. Method for cutting and placing nose wires in a facemask manufacturing process. U.S. Patent 10,143,246. 2018.

18. Khokhlenkova NV, Kovalenko SM, Azarenko JM, et al. Development of methodical approaches to the creation of the pharmacologically active bandage. 2017.

19. Li Z, Navarro-Alvarez N, Keeley EJ, et al. Non-invasive monitoring of skin inflammation using an oxygen-sensing paint-on bandage. Biomedical optics express. Biomed Opt Express. 2017;8(10):46404651.

20. Reese W, Ludwig R, Volk H, et al. Hybrid cord for use as reinforcement in a belt bandage of a pneumatic vehicle tire. U.S. Patent Application 15/503,741. 2017.

21. Anton-Sales I, D’Antin JC, Fernández-Engroba J, et al. Bacterial nanocellulose as a corneal bandage material: a comparison with amniotic membrane. Biomaterials Science. 2020.

22. Bayir Y, Un H, Ugan RA, et al. The effects of Beeswax, Olive oil and Butter impregnated bandage on burn wound healing. Burns. 2019;45(6):1410-1417.

23. Koonalinthip N, Sukthongsa A, Janchai S. Comparison of removable rigid dressing and elastic bandage for residual limb maturation in transtibial amputees: a randomized controlled trial. Archives of Physical Medicine and Rehabilitation. 2020;101(10):1683-1688.

24. Kolpakhchyan PG, Lobov BN, Mikitinskiy AP, et al. The production possibility of permanent magnet high speed electric generator rotors. 2018 X International Conference on Electrical Power Drive Systems (ICEPDS); 2018:1-5.

25. He Z, Zhou G, Byun JH, et al. Highly stretchable multi-walled carbon nanotube/thermoplastic polyurethane composite fibers for ultrasensitive, wearable strain sensors. Nanoscale. 2019;11(13):5884-5890.

26. Buan J, Willems R,. Method for providing negative pressure to a negative pressure wound therapy bandage. U.S. Patent 9,067,003. 2015.

27. Wang J, Jiu J, Nogi M, et al. A highly sensitive and flexible pressure sensor with electrodes and elastomeric interlayer containing silver nanowires. Nanoscale. 2015;7(7):2926-2932. 